\title{
On the Irrelevance of Financial Policy under Market Incompleteness and Trading Constraints*
}

\author{
Eva Cárceles Poveda ${ }^{\dagger} \quad$ SUNy at Stony Brook
}

February 26, 2006

\begin{abstract}
This paper studies the validity of the Modigliani and Miller Irrelevance proposition in the presence of incomplete markets and portfolio restrictions. If the economy is originally in equilibrium and the firm changes its financial plan, we show that there exist state-dependent trading limits under which financial policy is always irrelevant. In addition, the no short-selling constraint usually imposed on equity shares is innocuous in spite of being state-independent, whereas fixed portfolio restrictions on other assets always have real effects if they are part of the firm's capital structure. In this case, however, we find that the quantitative effects of financial policy are relatively small, since households are typically able to almost entirely offset the firm's actions by modifying their portfolio holdings.
\end{abstract}

Keywords: Financial policy, Incomplete markets, Trading constraints

JEL Classification: E44, G10, G32

\footnotetext{
${ }^{*}$ I am grateful to Herakles Polemarchakis for fruitful discussions on the topic.

${ }^{\dagger}$ Correspondence: Department of Economics, State University of New York, Stony Brook NY-117944384. Phone: 1-631-632-7533. Fax: 1-631-632-7516. Email: ecarcelespov@notes.cc.sunysb.edu. Web: http://ms.cc.sunysb.edu/ ecarcelespov/.
} 


\section{INTRODUCTION}

In a major contribution, Modigliani and Miller (1958), (1963) showed that financial policy could be irrelevant. In two subsequent papers, Stiglitz (1969), (1974) extended their partial equilibrium argument to a multi-period general equilibrium setup with uncertainty. Given one initial equilibrium, the latter author showed the existence of another equilibrium with different financial policies but the same firm values and real allocations. Whereas he already pointed out that market completeness was not needed for the result, a more rigorous analysis was presented later by DeMarzo (1988), who did not restrict the choices of the firm to debtequity ratios, but allowed them to take arbitrary positions in the asset markets.

Apart from the presence of perfectly competitive capital markets with no other frictions, such as bankruptcy, asymmetric information, taxes or transaction costs, the previous studies assume that there are no effective restrictions on the agent's portfolio strategies. While most of these assumptions still make sense in an infinite horizon incomplete markets setup, the absence of portfolio restrictions, combined with the open endness of the future, could easily lead to Ponzi schemes, implying that an equilibrium may not even exist. Given the importance of general equilibrium economies extending over infinite time in contemporary macroeconomic theory, the present paper relaxes the last assumption and studies the validity of the main irrelevance theorem in the presence of effectively binding portfolio constraints.

For comparison with the literature, we consider an infinite horizon setup with production, aggregate uncertainty, idiosyncratic risk and sequential asset trade. Each period, households receive idiosyncratic labor income shocks, against which they can imperfectly insure by trading in a finite number of assets subject to portfolio restrictions. Further, the representative firm determines the aggregate investment, which can be financed through retained earnings and through the issue of new securities.

As to the firm objective, we adopt the value maximization approach studied by Duffie and Shaffer (1986) and DeMarzo (1988). In essence, this requires that firms discount profits with a present value process that is consistent with security prices, in the sense that it does not allow for arbitrage opportunities. Whereas other firm objectives are clearly possible, our results do not depend on the firm objective. Moreover, Carceles-Poveda (2005) shows that the equilibrium with value maximizing firms is also an equilibrium in a framework where firms maximize period by period profits and households make the intertemporal investment decision. Given that this is the usual setup in the macro-finance literature, we choose to work with value maximization.

Our main results can be summarized as follows. First, if households are subject to the natural borrowing limit, there exist a continuum of equilibria where the firm has changed its financial policy and the households have modified their portfolio holdings to offset the firm's actions. Across these equilibria, the value of the firm and the real allocations are unchanged. Second, we show that there exist state dependent portfolio restrictions that are different 
from the natural borrowing limits and that still preserve the irrelevance of financial policy in spite of being occasionally binding. This is due to the fact that they leave the same set of households (un)constrained after the firm changes its policy. Interestingly, we find that the no short-selling constraint that is usually imposed on equity shares is innocuous in spite of being state-independent, whereas fixed portfolio restrictions on the other asset holdings always have real effects if the assets belong to the firm's capital structure.

Our theoretical results are illustrated with several numerical examples that compare the equilibrium allocations under different financial policies and portfolio restrictions. In particular, we compare economies where the firm can finance its investment with retained earnings and with the issue of new securities to economies where the firm does not use external financing. In both cases, we first characterize the state dependent limits under which financial policy is irrelevant and then analyze the effects of a change in financial policy under fixed portfolio restrictions.

In a model where two types of households can trade in equity shares, we find that the real effects of a change in financial policy are quantitatively very small. This is due to the fact that the portfolio restrictions on equity shares are rarely binding, even if they are relatively tight. Given this, households can almost entirely offset the firm's actions by modifying their portfolio holdings. We then study an economy where two types of households can only trade in risk free one period bonds. In this case, we find that leverage could potentially lead to more risk sharing, since a higher amount of outstanding debt implies that households can borrow relatively more. In addition, moving to an economy with leveraged firms is not necessarily Pareto worsening, since households with negative debt holdings face a lower interest rate that reduces their financial liabilities. In general, however, the consumption allocations are again relatively similar to the ones in the original equilibrium, since households are able to choose very similar portfolios to the ones that would offset the firm's actions.

Several remarks are worth noting. First, our quantitative results should be interpreted with care, since they only apply to our particular model with two types of agents. On the other hand, we conjecture that our general finding, that financial policy has relatively small real effects in the presence of portfolio restrictions, is not likely to change in the presence of a continuum of households. This is due to the fact that, in these type of models, the behavior of the main macroeconomic variables, such as the capital accumulation path, is mostly determined by the households that are unconstrained. Since these households would in general be able to offset the firm's actions by modifying their portfolio holdings, financial policy is likely to have relatively small effects in such a framework.

Second, our analysis abstracts from several important aspects such as the determination of the optimal capital structure, as well as from other restrictions such as taxes, asymmetric information and firm bankruptcy. On the other hand, a study of the quantitative importance of financial policy in models with incomplete markets and heterogeneous agents has been 
largely ignored in the literature. We therefore believe that our results constitute a first step towards this direction. In particular, we have shown that portfolio restrictions alone are not sufficient for generating sizesable effects of financial policy on the equilibrium allocations. Thus, incorporating other restrictions into our framework is a very interesting exercise that we leave for further research.

The rest of the paper is organized as follows. Chapter two presents the model and chapter three discusses our main irrelevance results. These are further illustrated with several numerical examples in chapter four, and chapter five summarizes and concludes.

\section{The Model}

We consider an infinite horizon economy with sequential asset trade. Time is discrete and indexed by $t=0,1,2 \ldots$ Further, the resolution of uncertainty is represented by an event-tree $N$. Each node $s^{t} \in N$, summarizing the history of the environment until date $t$, has a finite number $S$ of immediate successors denoted by $s^{t+1} \mid s^{t}$. We use the notation $s^{r} \mid s^{t}$ with $r \geq t$ to indicate that node $s^{r}$ belongs to the sub-tree with root $s^{t}$. Further, with the exception of the unique root node $s^{0}$ at $t=0$, each node has a unique predecessor, denoted by $s^{t-1}$. The probability of node $s^{t}$ is denoted by $\pi\left(s^{t}\right)$, with $\pi\left(s^{0}\right)=1$. In addition, $\pi\left(s^{r} \mid s^{t}\right)$ denotes the probability of $s^{r}$ given $s^{t}$. Throughout the section, we let $\{x\}=\left\{x\left(s^{t}\right)\right\}_{s^{t} \in N}$.

2.1. Financial Markets. At each date-state, there exist spot markets for a single consumption good and for a finite number $L$ of securities whose return is denominated in units of the good. Equity is indexed by $l=1$, whereas the assets indexed by $l \geq 2$ are other securities different from equity whose returns do not depend on the firm's financial policy.

Let $q\left(s^{t}\right) \in \mathbb{R}^{L}$ and $d\left(s^{t}\right) \in \mathbb{R}^{L}$ represent the vectors of security prices and dividends respectively. Holding $a_{l}\left(s^{t-1}\right)$ units of security $l \in L$ at the end of period $t-1$ entitles the owner to a one period return of $R_{l}\left(s^{t}\right) a_{l}\left(s^{t-1}\right)$ if date-state $s^{t}$ is realized, where ${ }^{1}$

$$
R_{l}\left(s^{t}\right)=\left[d_{l}\left(s^{t}\right)+q_{l}\left(s^{t}\right)\right] .
$$

A security traded at $s^{t}$ is of finite maturity if there exists a date $T$ such that $R_{l}\left(s^{r} \mid s^{t}\right)=0$ for all $s^{r} \mid s^{t}$ with $r \geq T$. Otherwise, the security is infinitely lived. Further, security markets are complete if the rank of the $S \times L$ matrix of returns is equal to $S$ at each node. In what follows, we assume that $L \leq S$, potentially allowing for incomplete markets.

The security price process $\{q\}$ is arbitrage free at $s^{t}$ if there does not exist a portfolio $a\left(s^{t}\right) \in \mathbb{R}^{L}$ with non-positive value $q\left(s^{t}\right)^{\prime} a\left(s^{t}\right) \leq 0$ and nonnegative payoffs $R\left(s^{t+1}\right)^{\prime} a\left(s^{t}\right) \geq 0$ for all $s^{t+1} \mid s^{t}$, with at least one strict inequality. In equilibrium, the absence of arbitrage at $s^{t}$ implies the existence of positive present value prices $\lambda\left(s^{t}\right)>0$ and $\lambda\left(s^{t+1}\right)>0$ for each

\footnotetext{
${ }^{1}$ Note that we are abstracting from securities that pay bundles of other securities, such as derivative securities. As shown by Detemple et all (1995), financial policy is not irrelevant in this case.
} 


\section{Financial Policy with Trading Constraints}

$s^{t+1} \mid s^{t}$, that satisfy the following equation:

$$
q\left(s^{t}\right)^{\prime}=\sum_{s^{t+1} \mid s^{t}} \frac{\lambda\left(s^{t+1}\right)}{\lambda\left(s^{t}\right)} R\left(s^{t+1}\right)^{\prime} .
$$

Given $(q, d)$, we let $\{\lambda\}$ be a process such that Eq. (2). Further, we denote by $Q_{s^{t}}(q, d)$ the set of such processes for the sub-tree with root $s^{t}$. Note that these present value processes can be used to evaluate future streams of consumption goods. In particular, for a non-negative stream $\{x\}$ with $x\left(s^{t}\right) \in \mathbb{R}_{+}$, the present value of the subsequent stream at $s^{t}$ with respect to some $\{\lambda\} \in Q_{s^{t}}(q, d)$ is given by:

$$
v_{x}\left(s^{t}, \lambda\right)=\sum_{r=1}^{\infty} \sum_{s^{t+r} \mid s^{t}} \frac{\lambda\left(s^{t+r}\right)}{\lambda\left(s^{t}\right)} x\left(s^{t+r}\right) .
$$

2.2. Households. The economy is populated by a representative firm and by a set $I$ of infinitely lived households that are indexed by $i \in I$. If $I$ is finite, there is a finite set of types with a continuum of identical agents within each type. Households have identical additively separable preferences over sequences of consumption $\left\{c^{i}\right\}$ of the form:

$$
U\left(\left\{c^{i}\right\}\right)=\sum_{t=0}^{\infty} \sum_{s^{t}} \pi\left(s^{t}\right) \beta^{t} u\left(c^{i}\left(s^{t}\right)\right)=E_{0} \sum_{t=0}^{\infty} \beta^{t} u\left(c^{i}\left(s^{t}\right)\right),
$$

where $\beta \in(0,1)$ is the discount factor and $E_{0}$ is the expectation conditional on information at date $t=0$. The period utility function $u(\cdot): \mathbb{R}_{+} \rightarrow \mathbb{R}$ is assumed to be strictly increasing, strictly concave and continuously differentiable, with $\lim _{c^{i} \rightarrow 0} u_{c^{i}}=\infty$, and $\lim _{c^{i} \rightarrow \infty} u_{c^{i}}=0$.

At each date, household $i \in I$ receives a labour endowment of $\epsilon^{i}\left(s^{t}\right)$, following a stochastic process with $S_{\epsilon}$ possible values. The individual labor income is therefore equal to $w^{i}\left(s^{t}\right)=$ $w\left(s^{t}\right) \epsilon^{i}\left(s^{t}\right)$, where $w\left(s^{t}\right)$ is the aggregate wage. At each node, household $i \in I$ chooses consumption $c^{i}\left(s^{t}\right) \in \mathbb{R}_{+}$and a portfolio $a^{i}\left(s^{t}\right) \in \mathbb{R}^{L}$ subject to the following constraints:

$$
\begin{gathered}
c^{i}\left(s^{t}\right)+q\left(s^{t}\right)^{\prime} a^{i}\left(s^{t}\right) \leq \omega^{i}\left(s^{t}\right) \\
\omega^{i}\left(s^{t+1}\right)=w^{i}\left(s^{t+1}\right)+R\left(s^{t+1}\right)^{\prime} a^{i}\left(s^{t}\right) \\
a_{l}^{i}\left(s^{t}\right) \geq \kappa_{l}^{i}\left(s^{t}\right) .
\end{gathered}
$$

Equation (5) is the standard budget constraint with sequential markets and Eq. (6) is the law of motion of individual wealth $\omega^{i}\left(s^{t}\right)$. To avoid Ponzi schemes, Eq. (7) imposes a limit of $\kappa_{l}^{i}\left(s^{t}\right)$ on the amount of security $l \in L$ that households can borrow. ${ }^{2}$

Using the no arbitrage present value prices, a particular trading restriction that we can impose on the total portfolio value $q\left(s^{t}\right)^{\prime} a^{i}\left(s^{t}\right)$ is the present value constraint, which is

\footnotetext{
${ }^{2}$ It is important to note that all our results (with a slight modification of the main proposition) still go through if the limits are imposed on the value of the security holdings $q_{l} a_{l}^{i}$.
} 
effectively never binding at any finite date. In particular, it is the tightest borrowing limit such that the portfolio holdings satisfy the budget constraint with $c^{i}\left(s^{t}\right) \in \mathbb{R}_{+}$for all $s^{t} \in N$. As shown by Santos and Woodford (1997), this constraint can be formally specified as follows:

$$
q\left(s^{t}\right)^{\prime} a^{i}\left(s^{t}\right) \geq \kappa^{i}\left(s^{t}\right), \text { where } \kappa^{i}\left(s^{t}\right)=-\inf _{\{\lambda\} \in Q_{s^{t}}(q, d)} v_{w^{i}}\left(s^{t}, \lambda\right) .
$$

2.3. Firms. At each node $s^{t}$, the representative firm uses capital $K\left(s^{t}\right) \in \mathbb{R}_{+}$and labor $L\left(s^{t}\right) \in(0,1)$ to produce a single good $y\left(s^{t}\right) \in \mathbb{R}_{+}$with the aggregate technology:

$$
y\left(s^{t}\right)=f\left(z\left(s^{t}\right), K\left(s^{t}\right), L\left(s^{t}\right)\right),
$$

where $z\left(s^{t}\right)$ is an aggregate productivity shock that follows a stochastic process with $S_{z}$ possible values. Given $z$, the production function $f(z, \cdot, \cdot): \mathbb{R}_{+}^{2} \rightarrow \mathbb{R}_{+}$is assumed to be continuously differentiable on the interior of its domain, strictly increasing, strictly concave in $K$ and homogeneous of degree one in $K$ and $L$. Capital depreciates at the constant rate $\delta$ and we also assume that $\lim _{K \rightarrow 0} f_{K}=\infty$ and $\lim _{K \rightarrow \infty} f_{K}=0$.

The firm owns the entire stock of capital and it undertakes the inter-temporal investment decision by solving a dynamic optimization problem. Unfortunately, the usual approach, that firms maximize their share value, is not well specified under market incompleteness. This is due to the fact that the available markets do not provide sufficient information to value future cash flows unambiguously. ${ }^{3}$ In what follows, we adopt the value maximization approach proposed by DeMarzo (1988) and Duffie and Shaffer (1986), which requires firms to discount their cash flows according to some no arbitrage present value price. The objective postulated by the previous authors can therefore be specified as follows:

$$
\operatorname{Max}_{\{K, L\}} \sum_{r=0}^{\infty} \sum_{s^{t+r}} \frac{\lambda\left(s^{t+r}\right)}{\lambda\left(s^{t}\right)} N_{f}\left(s^{t+r}\right) \text { for some }\{\lambda\} \in Q_{s^{t}}(q, d),
$$

where the net cash flow $N_{f}\left(s^{t}\right)$ is given by:

$$
N_{f}\left(s^{t}\right)=y\left(s^{t}\right)-w\left(s^{t}\right) L\left(s^{t}\right)+(1-\delta) K\left(s^{t-1}\right)-K\left(s^{t}\right) .
$$

While other objectives are clearly possible, none of our results will depend on the particular firm objective chosen. Moreover, Carceles-Poveda (2005a) shows that the equilibrium under the previous objective is also an equilibrium in an economy where households make the intertemporal investment decision and the firm maximizes period by period profits. ${ }^{4}$ Given that this last setup is the usual one in the macro-finance literature, we choose to work with value maximization. The previous optimization problem leads to the following first order

\footnotetext{
${ }^{3}$ See Carceles-Poveda (2005) for an extensive discussion of this issue. Further, see Dreze (1985) and Grossmann and Stiglitz $(1977,1980)$ for a review of the literature.

${ }^{4} \mathrm{~A}$ formal proof of this statement, extending the results in Carceles-Poveda (2005) to the presence of external finance, can be provided by the author upon request.
} 


\section{Financial Policy with Trading Constraints}

conditions, which determine the aggregate wage rate $\{w\}$ and the aggregate capital stock $\{K\}$ :

$$
\begin{gathered}
w\left(s^{t}\right)=f_{L}\left(z\left(s^{t}\right), K\left(s^{t-1}\right), L\left(s^{t}\right)\right) \\
1=\sum_{s^{t+1} \mid s^{t}} \lambda_{t}^{s^{t+1}}\left[f_{K}\left(z\left(s^{t+1}\right), K\left(s^{t}\right), L\left(s^{t+1}\right)\right)+1-\delta\right]
\end{gathered}
$$

As to the firm's financial policy, we assume that investment can be financed with retained earnings or with the issue new securities. If $A_{l}\left(s^{t}\right)$ represents the supply of security $l \in L$ at the end of period $t$, the relationship between real and financial decisions can therefore be expressed by the following accounting identity:

$$
\sum_{l \in L} d_{l}\left(s^{t}\right) A_{l}\left(s^{t-1}\right)=N_{f}\left(s^{t}\right)+\sum_{l \in L} q_{l}\left(s^{t}\right)\left[A_{l}\left(s^{t}\right)-A_{l}\left(s^{t-1}\right)\right] .
$$

In essence, Eq. (14) implies that the dividends paid by the firm at $s^{t}$ are equal to its net cash flow plus the net value of securities issued during period $t$. We assume that $A_{l}\left(s^{t}\right) \in \mathbb{R}_{++}$ if the security is infinitely lived whereas $A_{l}\left(s^{t}\right) \in \mathbb{R}_{+}$otherwise. ${ }^{5}$ Finally, a financial plan at $s^{t}$ is defined as a vector $\rho\left(s^{t}\right) \in \mathbb{R}^{L+1}$, where the first element $\rho_{0}$ is equal to 1 if the firm uses external finance and 0 otherwise. Moreover, $\rho_{l}\left(s^{t}\right) \in[0,1]$ and $\sum_{l \geq 1} \rho_{l}\left(s^{t}\right)=1$, where $\rho_{l}\left(s^{t}\right)$ for $l \geq 1$ is the fraction of the ex-dividend firm value $V\left(s^{t}\right)$ accounted for by asset $l \in L$. Therefore, we have that $q_{l}\left(s^{t}\right) A_{l}\left(s^{t}\right)=\rho_{l}\left(s^{t}\right) V\left(s^{t}\right)$, where:

$$
V\left(s^{t}\right)=\sum_{l \in L} q_{l}\left(s^{t}\right) A_{l}\left(s^{t}\right) .
$$

Note that $\rho_{0}=0$ implies that $\rho_{1}\left(s^{t}\right)=1$ and $\rho^{l}\left(s^{t}\right)=0$ for $l \geq 2$. In this case, equity is the only asset in the firm's capital structure but no new equity is issued. On the other hand, if $\rho_{0}=1$, then $\rho_{1}\left(s^{t}\right) \in[0,1]$ depending on the composition of the firm's capital structure. Note also that a policy with $\left\{\rho_{0}, \rho_{1}\right\}=\{0,1\}$ is different from a policy with $\left\{\rho_{0}, \rho_{1}\right\}=\{1,1\}$ even though equity is the only asset in the firm's capital structure in both cases. In particular, $q_{1}\left(s^{t}\right) A_{1}\left(s^{t}\right)=V\left(s^{t}\right)$ under the second policy, since new equity is issued, while $q^{1}\left(s^{t}\right)=V\left(s^{t}\right)$ under the first. The following result will prove to be useful.

Lemma 2.1. Under value maximization, the ex-dividend value of the firm is equal to the aggregate capital stock, i.e., $V\left(s^{t}\right)=K\left(s^{t}\right)$.

A sketch of the proof of the Lemma is provided in the appendix. In essence, it implies that the equilibrium firm value $V$ is equal to the capital stock $K$ under value maximization. Since this also implies that $q_{l}\left(s^{t}\right) A_{l}\left(s^{t}\right)=\rho_{l}\left(s^{t}\right) K\left(s^{t}\right)$, we can interpret $\left\{\rho_{l}\right\}$ for $l \in L$ as the fraction of the aggregate capital accounted for by each security. A general equilibrium is defined in what follows. When doing this, it is important to note that but we take the

\footnotetext{
${ }^{5}$ As shown by Santos and Woodford (1997) and Carceles-Poveda (2005), this assumption rules out the existence of price bubbles in the present setup.
} 
financial plan $\{\rho\}$ as given. In other words, we abstract from the determination of the optimal capital structure, an issue which is outside the scope of the present paper.

2.4. General Equilibrium. Let the economy be specified by a joint transition matrix for the shocks $\Pi$, a set of preferences $\succsim=\left(\succsim_{i}\right)_{i \in I}$, portfolio constraints $\{\kappa\}=\left\{\left(\kappa^{i}\right)_{i \in I}\right\}$ and initial values $\left(K_{0}, a_{0}, z_{0}, \epsilon_{0}\right)=\left(K\left(s^{0}\right),\left(a^{i}\left(s^{0}\right), \epsilon_{i}\left(s^{0}\right)\right)_{i \in I}, z\left(s^{0}\right)\right)$. The economy is then described by $E=\left(\succsim,\left(K_{0}, a_{0}, z_{0}, \epsilon_{0}\right), \Pi,\{\kappa\}\right)$.

Definition 2.1. The vector of processes $\left\{\left(c^{i}, a^{i}\right)_{i \in I}, q, w, K\right\}$ is a (value maximizing) competitive equilibrium for $E$ with financial policy $\{\rho\}$ if (i) for each $i \in I$ and for each $s^{t} \in N,\left\{c^{i}, a^{i}\right\}$ is optimal under the preferences $\succsim$ given $\{q, w\},\left(K_{0}, a_{0}, z_{0}, \epsilon_{0}\right)$, $\Pi$, and $\{\kappa\}$ (ii) $\{w, K\}$ satisfies the firm's optimality conditions (for some $\{\lambda\} \in Q_{s^{t}}(q, d)$ ), (iii) all markets clear, i.e.,

$$
\begin{gathered}
\sum_{i \in I} a_{l}^{i}\left(s^{t}\right)=A_{l}\left(s^{t}\right) \text { for all } s^{t} \in N \text { and all } l \in L \\
\sum_{i \in I} c^{i}\left(s^{t}\right)=y\left(s^{t}\right)+(1-\delta) K\left(s^{t-1}\right)-K\left(s^{t}\right) \text { for all } s^{t} \in N .
\end{gathered}
$$

\section{The Irrelevance of Financial Policy}

The irrelevance of financial policy in the absence of portfolio restrictions has been established by several authors (see Gottardi (1995), Stiglitz (1974), Duffie and Shaffer (1986) or DeMarzo (1988)). In the present section, we characterize state dependent portfolio restrictions under which financial policy is still irrelevant in spite of the fact that they are binding. Following Stiglitz (1974), the effects of a change in financial policy are analyzed given an initial equilibrium and a fixed investment plan for the firm. The following proposition summarizes our main results.

Proposition 2.1 Assume that there exists a (value maximizing) competitive equilibrium $\left\{\left(c^{i}, a^{i}\right)_{i \in I}, q, w, K\right\}$ with financial policy $\{\rho\}$. Hold the initial values, the exogenous shocks and the investment $\{K\}$ fixed and assume that households are subject to the following portfolio restrictions. Either (i) $q\left(s^{t}\right)^{\prime} a^{i}\left(s^{t}\right) \geq \kappa^{i}\left(s^{t}\right)$, where $\kappa^{i}\left(s^{t}\right)=-\inf _{\{\lambda\} \in Q_{s}(q, d)} v_{w^{i}}\left(s^{t}, \lambda\right)$ or (ii) $a_{l}^{i}\left(s^{t}\right) \geq \kappa_{l}^{i}\left(s^{t}\right)$, where:

$$
\begin{gathered}
\kappa_{1}^{i}\left(s^{t}\right)=\kappa_{\alpha}^{i}\left(s^{t}\right) A_{1}\left(s^{t}\right), \\
\kappa_{l}^{i}\left(s^{t}\right)=\kappa_{\beta_{l}}^{i}\left(s^{t}\right)+\alpha^{i}\left(s^{t}\right) A_{l}\left(s^{t}\right),
\end{gathered}
$$

while $\kappa_{\alpha}^{i}\left(s^{t}\right)$ and $\kappa_{\beta_{l}}^{i}\left(s^{t}\right)$ are arbitrary restrictions that do not depend on financial policy. Then, there exists another equilibrium where the firm has changed its financial policy, but the firm value and the real allocations are unchanged. Further, households have modified their asset holdings to offset the firms' actions as follows. For all $s^{t} \in N, i \in I$ and $l \in L$ :

$$
\Delta a_{l}^{i}\left(s^{t}\right)=\alpha^{i}\left(s^{t}\right) \Delta A_{l}\left(s^{t}\right)
$$


where $\alpha^{i}\left(s^{t}\right)=a_{1}^{i}\left(s^{t}\right) / A_{1}\left(s^{t}\right)$ represents the equity proportion hold by household $i \in I$.

The previous proposition identifies conditions on the portfolio constraints under which a change in financial policy has no effects on the firm value and the real allocations. Essentially, the proposition asserts the following. Assume that there exists an equilibrium with respect to some $\{\rho\}$ and the firm modifies the financial plan without changing the investment $\{K\}$. Households can then achieve the same consumption if they modify their asset holdings by their equity proportions times the value of the total asset change, that is, $\Delta a_{l}^{i}\left(s^{t}\right)=\alpha^{i}\left(s^{t}\right) \Delta A_{l}\left(s^{t}\right)$ for all $l \in L$ and all $s^{t} \in N$.

In the absence of binding trading restrictions, these portfolio changes are feasible and financial policy is therefore irrelevant. This is the case under condition (i), since the present value constraint is effectively never binding. Moreover, condition (ii) specifies other state dependent constraints under which financial policy is still be irrelevant in spite of the fact that they are binding. As we will see later, these restrictions leave the subset of households that is constrained unaffected across different financial policies. The proof of the proposition and a more detailed discussion of the results is provided in what follows.

\section{Proof of Proposition 2.1.}

To prove the proposition, we consider an initial equilibrium $\left\{\left(c^{i}, a^{i}\right)_{i \in I}, q, w, K\right\}$ with financial plan $\{\rho\}$ and assume that the firm changes its financial policy without altering $\{K\}$. We first show that (a) if $\left\{V,\left(q_{l}, d_{l}\right)_{l \geq 2}\right\}$ is unchanged after a change in financial policy, the set of budget feasible consumption allocations is the same as in the original equilibrium. This implies that the original consumption allocation is still optimal after the change in policy. Moreover, it is easy to show that markets still clear. We then show that (b) the portfolio restrictions satisfying conditions (i) or (ii) of the proposition allow for the portfolio changes in (20), while they leave the same set of households (un)constrained in the new equilibrium.

(a) To prove the first statement, consider any date-state $s^{t}$ and any household $i \in I$ with initial wealth $\omega^{i}\left(s^{t}\right)$. Further, let $C^{i}\left(s^{t}\right)=c^{i}\left(s^{t}\right)-w^{i}\left(s^{t}\right)$ and $\omega_{+}^{i}\left(s^{t}\right)=q\left(s^{t}\right)^{\prime} a^{i}\left(s^{t}\right)$ be the individual consumption net of labor payments and the end of period asset wealth respectively. The budget constraint of the household can be written as follows:

$$
C^{i}\left(s^{t}\right)+\omega_{+}^{i}\left(s^{t}\right)=\omega^{i}\left(s^{t}\right),
$$

where

$$
\begin{gathered}
\omega_{+}^{i}\left(s^{t}\right)=\alpha^{i}\left(s^{t}\right) V\left(s^{t}\right)+\sum_{l \geq 2} q_{l}\left(s^{t}\right)\left[a^{i}\left(s^{t}\right)-\alpha^{i}\left(s^{t}\right) A_{l}\left(s^{t}\right)\right] \\
\omega^{i}\left(s^{t}\right)=\left[N_{f}\left(s^{t}\right)+V\left(s^{t}\right)\right] \alpha^{i}\left(s^{t-1}\right)+\sum_{l \geq 2} R^{l}\left(s^{t}\right)\left[a^{i}\left(s^{t-1}\right)-\alpha^{i}\left(s^{t-1}\right) A_{l}\left(s^{t}\right)\right] .
\end{gathered}
$$

Since the firm does not modify $\{K\}$, the individual labor income $\left\{\left(w^{i}\right)_{i \in I}\right\}$ and the net cash flow $\left\{N_{f}\right\}$ remain unchanged, whereas $\{w, K\}$ still satisfy the firm's optimality 
conditions. Second, if the vector $\left\{V,\left(q_{l}, d_{l}\right)_{l \geq 2}\right\}$ remains unchanged, the change in asset holdings defined by $(20)$ is feasible. To see why this is the case, let the caret bearing variables denote the new allocations. Since (20) implies that $\Delta a_{l}^{i}\left(s^{t}\right)=\alpha^{i}\left(s^{t}\right) \Delta A_{l}\left(s^{t}\right)$ for all $l \in L$ and all $s^{t} \in N$, we have that:

$$
\begin{aligned}
& \widehat{\alpha}^{i}\left(s^{t}\right)=\frac{\widehat{a}_{1}^{i}\left(s^{t}\right)}{\widehat{A}_{1}\left(s^{t}\right)}=\frac{a_{1}^{i}\left(s^{t}\right)+\alpha^{i}\left(s^{t}\right) \Delta A_{1}\left(s^{t}\right)}{\widehat{A}_{1}\left(s^{t}\right)}=\frac{\alpha^{i}\left(s^{t}\right)\left(A_{1}\left(s^{t}\right)+\Delta A_{1}\left(s^{t}\right)\right)}{\widehat{A}_{1}\left(s^{t}\right)}=\alpha^{i}\left(s^{t}\right) \\
& {\left[\widehat{a}_{l}^{i}\left(s^{t}\right)-\widehat{\alpha}^{i}\left(s^{t}\right) \widehat{A}_{l}\left(s^{t}\right)\right]=\left[a_{l}^{i}\left(s^{t}\right)+\Delta a_{l}^{i}\left(s^{t}\right)-\alpha^{i}\left(s^{t}\right)\left(A_{l}\left(s^{t}\right)+\Delta A_{l}\left(s^{t}\right)\right)\right]} \\
& =\left[a_{l}^{i}\left(s^{t}\right)-\alpha^{i}\left(s^{t}\right) A_{l}\left(s^{t}\right)\right] \text { for } l \geq 2 \text {. }
\end{aligned}
$$

Clearly, this implies that $\widehat{\omega}_{+}^{i}\left(s^{t}\right)=\omega_{+}^{i}\left(s^{t}\right)$, whereas the allocation $\widehat{c}^{i}\left(s^{t}\right)=c^{i}\left(s^{t}\right)$ is budget feasible at $s^{t}$. In addition, the next period wealth will be given by:

$$
\widehat{\omega}^{i}\left(s^{t+1}\right)=\left[N_{f}\left(s^{t+1}\right)+V\left(s^{t+1}\right)\right] \widehat{\alpha}^{i}\left(s^{t}\right)+\sum_{l \geq 2} R_{l}\left(s^{t+1}\right)\left[\widehat{a}_{l}^{i}\left(s^{t}\right)-\widehat{\alpha}^{i}\left(s^{t}\right) \widehat{A}_{l}\left(s^{t}\right)\right]=\omega^{i}\left(s^{t+1}\right) .
$$

Thus, households can modify the asset holdings at $s^{t+1} \mid s^{t}$ according to (20) and leave $\omega_{+}^{i}\left(s^{t+1}\right)$ unchanged, in which case $\widehat{c}^{i}\left(s^{t+1}\right)=c^{i}\left(s^{t+1}\right)$ is again feasible at $s^{t+1} \mid s^{t}$. Using the same arguments for every node, it becomes clear that the consumption opportunity set is unchanged after the change in financial policy. Since the original consumption allocation is an equilibrium, the same consumption allocation is optimal, and so are the portfolio changes in (20). Further, market clearing for the good is still satisfied, since $\sum_{i \in I} \alpha^{i}\left(s^{t}\right)=1$ and:

$$
\sum_{i \in I} \widehat{a}_{l}^{i}\left(s^{t}\right)=\left[\sum_{i \in I}\left(a_{l}^{i}\left(s^{t}\right)+\alpha^{i}\left(s^{t}\right) \Delta A_{l}\left(s^{t}\right)\right)\right]=\left[A_{l}\left(s^{t}\right)+\Delta A_{l}\left(s^{t}\right)\right]=\widehat{A}_{l}\left(s^{t}\right) \text { for } l \in L .
$$

Given that all markets clear and that the allocations are optimal, we have found a new equilibrium with a different financial plan $\{\widehat{\rho}\}$. Note that the same vector $\left\{V,\left(q_{l}, d_{l}\right)_{l \geq 2}\right\}$ is consistent with the household allocations. First, $\left\{d_{l}\right\}$ remains unchanged for $l \geq 2$ by assumption, since it is independent on the firm's financial policy. Second, $\left\{q_{l}\right\}$ for $l \geq 2$ is a function of $\left\{d_{l}\right\}$ and on the pricing kernel, which depends on the individual consumptions and also remains unchanged. Finally, $\{V\}=\{K\}$ is clearly consistent and it implies that $\widehat{q}_{1}\left(s^{t}\right) \widehat{A}_{1}\left(s^{t}\right)=q_{1}\left(s^{t}\right) A_{1}\left(s^{t}\right)$ for all $s^{t} \in N$.

(b) We now prove the statement in (b). First, since the present value constraint is effectively never binding, the statement is trivially satisfied under condition (i). Second, assume that households are subject to portfolio restrictions that satisfy condition (ii). Let $a_{1}^{i}\left(s^{t}\right)>\kappa_{1}^{i}\left(s^{t}\right)=\kappa_{\alpha}^{i}\left(s^{t}\right) A_{1}\left(s^{t}\right)$ in the original equilibrium. This implies that $\alpha^{i}\left(s^{t}\right)>$ $\kappa_{\alpha}^{i}\left(s^{t}\right)$ and therefore that $\widehat{\alpha}^{i}\left(s^{t}\right)=\alpha^{i}\left(s^{t}\right)>\kappa_{\alpha}^{i}\left(s^{t}\right)$. Using the definition of $\widehat{\alpha}^{i}\left(s^{t}\right)$, it follows that:

$$
\widehat{a}_{1}^{i}\left(s^{t}\right)>\kappa_{\alpha}^{i}\left(s^{t}\right) \widehat{A}_{1}\left(s^{t}\right)=\widehat{\kappa}_{1}^{i}\left(s^{t}\right) .
$$




\section{Financial Policy with Trading Constraints}

Similarly, if $a_{1}^{i}\left(s^{t}\right)=\kappa_{1}^{i}\left(s^{t}\right)$, we have that $\widehat{\alpha}^{i}\left(s^{t}\right)=\kappa_{\alpha}^{i}\left(s^{t}\right)$ and $\widehat{a}_{1}^{i}\left(s^{t}\right)=\widehat{\kappa}_{1}^{i}\left(s^{t}\right)$. Thus, the portfolio constraint on equity holdings leaves the same households (un)constrained after a change in financial policy. A similar argument can be used for the other assets. In particular, let $a_{l}^{i}\left(s^{t}\right) \geq \kappa_{l}^{i}\left(s^{t}\right)=\kappa_{\beta_{l}}^{i}\left(s^{t}\right)+\alpha^{i}\left(s^{t}\right) A_{l}\left(s^{t}\right)$. After the change in financial policy, we have that:

$$
\begin{aligned}
\widehat{a}_{l}^{i}\left(s^{t}\right) & =\left(a_{l}^{i}\left(s^{t}\right)+\alpha^{i}\left(s^{t}\right) \Delta A_{l}\left(s^{t}\right)\right) \geq \kappa_{\beta_{l}}^{i}\left(s^{t}\right)+\alpha^{i}\left(s^{t}\right)\left(A_{l}\left(s^{t}\right)+\Delta A_{l}\left(s^{t}\right)\right) \\
& =\kappa_{\beta_{l}}^{i}\left(s^{t}\right)+\alpha^{i}\left(s^{t}\right) \widehat{A}_{l}\left(s^{t}\right)=\widehat{\kappa}_{l}^{i}\left(s^{t}\right) \text { for all } l \in L
\end{aligned}
$$

As we see, this again implies that the same households will be (un)constrained in asset $l \geq 2$ in the new equilibrium. Given this, the irrelevance of financial policy is also preserved under the state dependent portfolio constraints satisfying condition (ii)

As shown by the proposition, financial policy is irrelevant under two types of restrictions. One of them is the present value constraint, which is effectively never binding in equilibrium. Alternatively, one can impose state dependent restrictions on the individual asset holdings. These have an individual component $\left\{\kappa_{\alpha}^{i}\right\}$ and $\left\{\kappa_{\beta_{l}}^{i}\right\}$, which is allowed to be arbitrary. In addition, they have an aggregate component that depends on the firm's financial policy $\{\rho\}$ (or $\{A\}$ ). Interestingly, the fact that $\left\{\kappa_{\alpha}^{i}\right\}$ is allowed to be arbitrary implies that we can set it to $\kappa_{\alpha}^{i}\left(s^{t}\right)=0$ for all $s^{t} \in N$, in which case $\kappa_{1}^{i}\left(s^{t}\right)=0$ for all $s^{t} \in N$. Thus, the no short-selling constraint that is usually imposed on equity is innocuous in spite of being fixed. On the other hand, an arbitrary constraint of $\left\{\kappa_{\beta_{l}}^{i}\right\}$ on other assets will only preserve irrelevance if $\Delta \rho_{l}\left(s^{t}\right)=0$ or $\Delta A_{l}\left(s^{t}\right)=0$, whereas it will have real effects otherwise.

While the existing literature on incomplete markets with heterogeneous households has largely ignored the effects of financial policy, the trading limits usually imposed are stateindependent and occasionally binding. Given this, financial policy will in general have both real and financial effects. A further characterization of the state dependent limits that preserve irrelevance and a study of the potential quantitative effects of financial policy under different portfolio restrictions is provided in the next section.

\section{Numerical EXAmples}

This section studies several examples that differ in the financial policies of the firm and the trading constraints faced by the households. The purpose of the section is to illustrate the results of the proposition and the potential effects of financial policy when the irrelevance conditions are not satisfied. Since we have chosen to work with a rather simple model and a stylized calibration, the quantitative findings apply to our particular model and should therefore be interpreted with care.

We assume that the economy is populated by a single value maximizing firm and by two types of households, that is, $I=2$. Further, there are only two assets, equity shares of the firm or risk free one period bonds. A financial plan is therefore given by a vector 
$\{\rho\}=\left\{\rho_{0}, \rho_{1}, \rho_{2}\right\}$. Finally, we study economies where households can only trade in one asset, since the portfolio constraints are rarely binding when households are allowed to trade in both equity and bonds.

The time period is one quarter, and the discount factor and depreciation rate are set to $\beta=0.99$ and $\delta=0.025$ to approximately match the US average interest rate of $4 \%$ and the investment to capital ratio of 0.025 during the postwar period. The production function is assumed to be Cobb Douglas, with a constant capital share of $\alpha=0.36$. Further, the utility functions of the households and the firm are assumed to be of the constant relative risk aversion class, with a risk aversion coefficient of $\gamma=1$.

Finally, the exogenous shock processes are assumed to be independent. The aggregate technology shock is assumed to follow a two state Markov chain with $z \in\left\{z_{l}, z_{h}\right\}=$ $\{0.99,1.01\}$ and a symmetric transition matrix with $\pi_{l l}=\pi_{h h}=87.5$, which approximately replicates the average length of business cycles. As to the idiosyncratic income process, it is assumed to follow a seven state Markov chain. Further, the values and transition matrix are obtained by using the Hussey and Tauchen (1991) procedure to discretize the process:

$$
\epsilon^{\prime}=\left(1-\psi_{\epsilon}\right) \mu_{\epsilon}+\psi_{\epsilon} \epsilon+u, u \sim N\left(0, \sigma_{u}^{2}\right) .
$$

The shock parameters are set to $\psi_{\epsilon}=0.956$ and $\sigma_{u}^{2}=0.082$, corresponding to quarterly adjusted numbers from annual data estimates of the idiosyncratic income process in the literature. Using the previous parameter values, the solution to the model is computed numerically using the Parameterized Expectations Approach (PEA), originally proposed by DenHaan and Marcet (1990). In essence, the algorithm iteratively approximates the conditional expectations of the model with flexible functions of the state variables of the model and of a set of parameters. Further, the solution parameter values ensure that, if households use them to make predictions, the approximating functions yield the best forecasts of the functions inside the expectations. A more detailed description of the algorithm is provided in the appendix.

4.1. An Economy with Trade in Equity Shares. In this example, equity is the only asset traded, whereas the firm can choose between retained earnings and the issue of common stock to finance investment. The accounting identity is therefore given by:

$$
d_{1}\left(s^{t}\right) A_{1}\left(s^{t-1}\right)=N_{f}\left(s^{t}\right)+q_{1}\left(s^{t}\right)\left[A_{1}\left(s^{t}\right)-A_{1}\left(s^{t-1}\right)\right]
$$

Two different financial policies are considered. In the first case, denoted by economy one, the number of outstanding equity shares is assumed to be constant and it is normalized to one, that is, $A_{1}\left(s^{t}\right)=1$ for all $s^{t} \in N$. This implies that investment is entirely financed with retained earnings. Moreover, the individual equity proportions are equal to the equity shares, that is, $\alpha^{i}\left(s^{t}\right)=a^{i}\left(s^{t}\right)$, whereas the dividends paid by the firm are equal to its net cash flow, $d_{1}\left(s^{t}\right)=N_{f}\left(s^{t}\right)$, as usual in the literature. 


\section{Financial Policy with Trading Constraints}

In the second case, denoted by economy two, the firm is assumed to pay a fraction of gross profits $y\left(s^{t}\right)-w\left(s^{t}\right) l\left(s^{t}\right)$ out as dividends, while it uses both retained earnings and equity issue to finance its investment. In sum, we are comparing the policies $\{\rho\}$ and $\{\hat{\rho}\}$, where $\rho_{0}=0, \rho_{1}\left(s^{t}\right)=1$ and $\rho_{2}\left(s^{t}\right)=0$, whereas $\hat{\rho}^{0}=1, \widehat{\rho}_{1}\left(s^{t}\right)=1$ and $\widehat{\rho}_{2}\left(s^{t}\right)=0$ for all $s^{t} \in N$.

Concerning the trading constraints, we consider two different cases. In the first, we require that $a^{i}\left(s^{t}\right) \geq \kappa^{i}\left(s^{t}\right)$, where $\kappa^{i}\left(s^{t}\right)=\kappa_{\alpha}^{i} A_{1}\left(s^{t}\right)$ for some arbitrary $\kappa_{\alpha}^{i}$. According to the proposition, financial policy will be irrelevant in this case, and the same real allocations will be achieved when moving from economy one to economy two. In the second case, we require that $a^{i}\left(s^{t}\right) \geq \kappa^{i}\left(s^{t}\right)=\kappa_{\alpha}^{i}$ for some arbitrary fixed $\kappa_{\alpha}^{i}$. As shown by the proposition, as long as $\kappa_{\alpha}^{i} \neq 0$, financial policy will be relevant. Given that the effects are likely to be stronger with tighter limits, we consider relatively tight constraints of $\kappa_{\alpha}^{i}=0.3$ and $\kappa_{\alpha}^{i}=0.4$.

Figures 1 and 2 display a sample period of some of the relevant variables in the two economies when the constraint is state dependent and equal to $\kappa^{i}\left(s^{t}\right)=0.3 A_{1}\left(s^{t}\right)$. The first two panels of the figures display the equity share proportions $\left\{\alpha^{i}\right\}$ and the consumption allocations $\left\{c^{i}\right\}$ of the two households. Further, the third panels display the individual equity holdings $\left\{a^{i}\right\}$ and the total amount of outstanding equity $\left\{A_{1}\right\}$, which is equal to one in the first economy, while it fluctuates around its mean in the second, assumed to be one for comparative purposes.

\section{$<$ Insert Figures 1 and 2 here $>$}

As predicted by the proposition, the first two variables are identical across economies in spite of the fact that financial policy is different, while the equity shares $\left\{a^{i}\right\}$ differ in the two cases. In particular, these are equal to $\left\{a^{i}\right\}=\left\{\alpha^{i}\right\}$ in the first economy, given that $A_{1}\left(s^{t}\right)=1$ for all $s^{t} \in N$, while they increase (decrease) in the second economy when the total amount of outstanding equity increases (decreases). As stated by the proposition, the adjustment of equity shares in economy 2 is equal to $\Delta a^{i}\left(s^{t}\right)=\alpha^{i}\left(s^{t}\right) \Delta A_{1}\left(s^{t}\right)$, allowing households to "undo" the firm's actions and to maintain the same consumption as in the first economy.

It is important to note that this adjustment in equity shares is only possible due to the fact that households are subject to a state dependent constraint. This constraint is depicted by the dashed line in the third panel of the figures and it is equal to $\kappa^{i}\left(s^{t}\right)=0.3 A_{1}\left(s^{t}\right)$. Since equity is always equal to one in the first economy, however, the constraint is simply $\kappa^{i}\left(s^{t}\right)=0.3$ in this case. To illustrate the importance of the state dependent limit, Figure 3 depicts the equity proportions in the two economies for the cases where the constraint is again state dependent and equal to $\kappa^{i}\left(s^{t}\right)=0.4 A_{1}\left(s^{t}\right)$ and for the case where it is fixed and equal to $\kappa^{i}\left(s^{t}\right)=0.4$.

$<$ Insert Figure 3 here $>$ 
The first two panels of the figure display the equity proportions chosen in the two economies when the state dependent constraint is imposed. Since financial policy is irrelevant in this case, they are identical. Whereas the equity proportions are still the same in economy 1 with the fixed constraint of $\kappa^{i}\left(s^{t}\right)=0.4$, the third panel of the figure reflects that households are not able to maintain the same equity proportions in economy 2. Note also that a fixed constraint of $a^{i}\left(s^{t}\right) \geq 0.4$ on the equity holdings implies that $\left\{\alpha^{i}\right\}$ is effectively subject to a state-dependent limit of $\alpha^{i}\left(s^{t}\right) \geq 0.4 / A_{1}\left(s^{t}\right)$, which is depicted by the dashed line. In spite of the fact that households cannot achieve the same consumption in the second economy, our results show that the allocations are very similar to the ones in economy 1. This is also reflected in Table 1, displaying the relative deviations to and the correlations with output of some of the macroeconomic variables under the fixed limit.

\section{$<$ Insert Table 1 here $>$}

As we see, all the statistics are very similar across the two economies. First, this is due to the fact that the portfolio constraints are not binding often in spite of being relatively tight. Second, the differences in portfolio allocations that are generated by the presence of financial policy do not lead to significantly different wealth levels. In other words, even under relatively tight trading limits, the real effects of external financing seem to be quantitatively very small when households can trade in equity shares of the firm. We also see that the relative variability of individual consumption is almost one half of the relative variability of the individual labor income. Thus, as usual in models with incomplete markets, households can achieve a relatively high insurance by trading in firm equity.

4.2. An Economy with Trade in Risk Free One Period Bonds. In the present example, we again compare two different economies that differ in the financial policies of the firm. In both cases, the amount of outstanding equity is normalized to one, that is, $A_{1}\left(s^{t}\right)=1$ for all $s^{t} \in N$. We assume that households can only trade in risk free one period bonds to insure against uncertainty, while they receive one half of the total dividends on equity every period. Further, the firm can finance its investment through retained earnings and through the issue of new debt. If we let $A_{2}\left(s^{t}\right) \geq 0$ and $R_{2}\left(s^{t}\right)$ be the total amount of risk free bonds and the risk free rate respectively, the accounting identity is given by:

$$
d_{1}\left(s^{t}\right)=N_{f}\left(s^{t}\right)+A_{2}\left(s^{t}\right)-R_{2}\left(s^{t}\right) A_{2}\left(s^{t-1}\right)
$$

We compare two different financial policies. In the first economy, investment is entirely financed by retained earnings, implying that $A_{2}\left(s^{t}\right)=0$ for all $s^{t} \in N$. In the second economy, the dividends on equity are again a fraction of gross profits, while the firm can finance investment with retained earnings and with the issue of new debt. In sum, we compare the financial policies $\{\rho\}$ and $\{\hat{\rho}\}$, where $\rho_{0}=0, \rho_{1}\left(s^{t}\right)=1$ and $\rho_{2}\left(s^{t}\right)=0$, whereas $\widehat{\rho}_{0}=1$, 


\section{Financial Policy with Trading Constraints}

$\widehat{\rho}_{1}\left(s^{t}\right) \in[0,1]$ and $\widehat{\rho}_{2}\left(s^{t}\right) \in[0,1]$ for all $s^{t} \in N$. Note that, in both economies, $\alpha^{i}\left(s^{t}\right)=0.5$ for all $s^{t} \in N$, since no equity is issued or traded. ${ }^{6}$

Concerning the trading limits, we consider constraints of the form $a^{i}\left(s^{t}\right) \geq \kappa^{i}\left(s^{t}\right)=\kappa_{\beta}^{i}$ and $a^{i}\left(s^{t}\right) \geq \kappa^{i}\left(s^{t}\right)=\kappa_{\beta}^{i}+\alpha^{i}\left(s^{t}\right) A_{2}\left(s^{t}\right)$, where $\kappa_{\beta}^{i}=-1$. According to the proposition, financial policy will be relevant when moving from the first economy to the second economy under the first type of constraints, while it will be irrelevant under the state dependent limits.

Figure 4 and 5 displays the bond holdings chosen by the households in the first economy, where the firm finances investment entirely with retained earnings, and in the second economy, where the firm can also issue debt. In both cases, we have imposed a fixed constraint of $a^{i}\left(s^{t}\right) \geq-1$ on the individual bond holdings. The second panel of Figure 5 displays again the bond holdings of the second economy under the fixed constraint whereas the first panel displays the bond holdings with the state dependent constraints that preserve the irrelevance of financial policy. We denote them by irrelevance bond holdings.

\section{$<$ Insert Figures 4 and 5 here $>$}

Consider first the case where financial policy is irrelevant. According to the proposition, when the firm issues debt, households modify their bond holdings by $\Delta a^{i}\left(s^{t}\right)=$ $\alpha^{i}\left(s^{t}\right) \Delta A_{2}\left(s^{t}\right)$. Since the original debt in economy 1 is zero, the irrelevance bond holdings are given by $\widehat{a}_{i}\left(s^{t}\right)=a^{i}\left(s^{t}\right)+0.5 A_{2}\left(s^{t}\right)$. This implies that, when the firm issues debt, household holds their old bond holdings plus one half of the new debt. As reflected by the first two panels of the figures, we see that the individual bond holdings in economy 1 are shifted up by the same amount after the firm issues debt. Note also that the state dependent constraints that preserve irrelevance are given by $\kappa^{i}\left(s^{t}\right)=-1+0.5 A_{2}\left(s^{t}\right)$, clearly implying that the same households are (un)constrained after the change in financial policy. Although this is not apparent from the previous figure, this constraint varies substantially with the aggregate state of the economy, as shown in Figure 6.

\section{$<$ Insert Figure 6 here $>$}

Consider now the case where we impose a fixed limit of $\kappa^{i}\left(s^{t}\right)=-1$ in the two economies. In this case, the original allocations are not optimal any more, since the firm value and the aggregate capital stock are affected by a change in financial policy. As reflected by the second panel of Figure 5, households hold more debt and in particular borrow (lend) more than required for irrelevance after the firm issues debt. Note that this is only possible due to the fact that the state dependent constraint is tighter than the fixed limit, as reflected by Figure 6. In a sense, the original limit is "relaxed" when the firm if leveraged, potentially

\footnotetext{
${ }^{6}$ Similar results can be obtained if we assume that debt is a constant fraction of the aggregate capital stock. We therefore do not discussed this case in what follows.
} 
generating a higher risk sharing. Table 2 displays the macroeconomic statistics in the two economies under the fixed limit.

$<$ Insert Table 2 here $>$

As we see, consumption is less volatile in the leveraged economy, indicating that risk sharing is somewhat higher in this case. As in the previous example, however, the allocations are again relatively similar across the two economies. As reflected in Figure 5, this is due to the fact that the portfolio allocations are relatively similar, whereas the trading constraints do still not bind very often. In other words, the quantitative effects of financial policy are again relatively small. Figure 7 explores the welfare effects of changing the financial policy from the economy with no debt to a leveraged economy.

\section{$<$ Insert Figure 7 here $>$}

The left panel depicts the value functions as a function of the aggregate capital stock of a household that initial holds $a^{i}\left(s^{t-1}\right)=-1$ and either the lowest $\left(\epsilon_{1}\right)$, the intermediate $\left(\epsilon_{4}\right)$ or the highest $\left(\epsilon_{7}\right)$ income shock. The right panel depicts the value functions for the trading partner, whose initial bond holdings are equal to $a^{i}\left(s^{t-1}\right)=A_{2}\left(s^{t-1}\right)+1$. By the symmetry of the idiosyncratic shock, this implies that the agent represented by the bottom line on the left panel coexists with the agent represented by the top line on the right panel. Even though the differences are very small, the figures reflect that welfare is always higher for a household that holds negative assets when the firm is leveraged, whereas the opposite is true for the household that holds positive debt. To explain these results note that the budget constraint of the households is given by the following expression in both economies:

$$
c^{i}\left(s^{t}\right)+a^{i}\left(s^{t}\right)=d\left(s^{t}\right) 0.5+R_{2}\left(s^{t}\right) a^{i}\left(s^{t-1}\right)+w\left(s^{t}\right) \epsilon_{i}\left(s^{t}\right)
$$

As we see, households receive both labor and asset income, with the last being equal to one half of the equity dividends and to the interest rate on the initial debt holdings. Our experiment looks at welfare when we move from an economy where debt is in zero net supply to an economy where the firm issues debt. Clearly, any effect on dividends will have the same effect on the two households.

Consider first a household that holds negative debt (left panel). When the firm issues more debt, both the interest rate on debt and the return on capital decrease, since the aggregate capital stock is lower when the firm is leveraged. First, the lower interest rate on debt implies that households with a negative debt have lower asset liabilities, whereas the households that hold positive debt receive less interest. Second, while the change in the aggregate capital decreases wages, the interest rate effect dominates. This is confirmed by results not depicted here, who illustrate that welfare does not differ significantly across 


\section{Financial Policy with Trading Constraints}

households in the two economies when they hold the same amount of debt. Given this, and the fact that risk sharing is somewhat higher in the leveraged economy implies that households with negative debt holdings prefer the leveraged firm. In other words, when households are heterogeneous, moving to a leveraged economy might not be necessarily Pareto worsening.

\section{Summary and Conclusions}

The present work has investigated the consequences of the firm's financial policy in the context of an infinite horizon model with market incompleteness and trading constraints. Whereas financial policy is irrelevant in the presence of constraints that are effectively never binding, such as the natural borrowing constraint, our work has shown that there exist statedependent trading constraints such that the irrelevance of financial policy is not violated in spite of the fact that they are occasionally binding. This is due to the fact that these trading limits are equally restrictive after the firm changes its financial policy.

Our results are illustrated with several numerical examples that compare economies where the firm does not use external finance with economies where the firm can issue equity or debt to finance its investment. In general, we find that a change in financial policy is likely to have small quantitative effects. This is due to the fact that households are typically able to almost entirely "undo" the actions of the firm by modifying their portfolio holdings. This is particularly true when households can trade in equity shares of the firm, in which case the portfolio constraints are rarely binding even if they are relatively tight. In addition, when households can only trade in debt, moving to an economy with leveraged firms might potentially lead to more risk sharing. Moreover, it might not be Pareto worsening, since a lower interest rate benefits the households with negative asset holdings.

\section{APPENDIX}

Proof of Lemma 2.1. To see that $\{V\}=\{K\}$ under value maximization, we can multiply Eq. (13) with $K\left(s^{t}\right)$ and rewrite it as follows:

$$
K\left(s^{t}\right)=\sum_{s^{t+1} \mid s^{t}} \lambda_{t}^{s^{t+1}}\left[N_{f}\left(s^{t+1}\right)+K\left(s^{t+1}\right)\right]=\sum_{r=1}^{\infty} \sum_{s^{t+r} \mid s^{t}} \lambda_{t}^{s^{t+r}}\left[N_{f}\left(s^{t+r}\right)\right]
$$

where we have used the definition of $\left\{N_{f}\right\}$ in (11). On the other hand, we can use Eq. (2) to rewrite the ex-dividend firm value as follows:

$$
V\left(s^{t}\right)=\sum_{s^{t+1} \mid s^{t}} \lambda_{t}^{s^{t+1}} \sum_{l \in L}\left[d_{l}\left(s^{t+1}\right)+q_{l}\left(s^{t+1}\right)\right] A_{l}\left(s^{t}\right)=\sum_{r=1}^{\infty} \sum_{s^{t+r} \mid s^{t}} \lambda_{t}^{s^{t+r}}\left[N_{f}\left(s^{t+r}\right)\right]
$$

where we have used accounting identity in (14) and the fact that $\{\lambda\} \in Q_{s^{t}}(q, d)$. The previous two equations show that $\{V\}=\{K\}$. 


\section{Solving the model with the PEA algorithm}

The essence of the PEA approach is to parameterize the expectations in the equilibrium system of equations as functions of the state variables $\{S\}$, which are known at period $t$, in order to be able to solve for the endogenous variables $\{x\}$. In particular, if $E_{j}$ denotes the jth expectation in the model, we are looking for time invariant functions $f_{j}$ such that:

$$
E_{j}\left[\phi_{j}\left(x_{t+1}\right) \mid S_{t}\right]=f_{j}\left(S_{t}\right) \text { for all } j
$$

To find a solution $\{x\}$, we need to find an approximation of $f_{j}$, i.e., we need to choose a class of functions that can approximate $f_{j}$ arbitrarily well, and fix the degree of approximation. An alternative is to use exponentiated polynomials, for which one can increase the degree of accuracy by increasing their order. This results in a function $g_{j}$ of the state variables and of a vector of parameters $\beta_{j}$, determining the explanatory power of each state in the expectation term. Thus, the parameterized expectation is given by $E_{j}\left[\phi_{j}\left(x_{t+1}\right) \mid S_{t}\right]=g_{j}\left(\beta_{j}, S_{t}\right)$. Finally, to find a vector of parameters $\beta_{j}$ that is consistent with the true expectation, the following iterative procedure is repeated until convergence:

(i) We first replace the true conditional expectations $E_{j}$ with the finitely parameterized functions $g_{j}$ using the parameters obtained in the previous iteration and solve for the endogenous variables. In particular, one obtains a time series of length $T$ for all endogenous variables, i.e., a series $\{x(\beta)\}_{t=1}^{T}$ representing the value of the endogenous variables if agents use $g\left(\beta, S_{t}\right)$ to make their forecasts. To do this, initial values for the endogenous states, as well as $T$ random shocks are needed. These shocks are only generated once and kept the same for every iteration.

(ii) The time series for the variables are used to estimate the parameters of the functions $g\left(\beta, S_{t}\right)$. To ensure consistency with the true expectations, the following nonlinear least square minimization is computed:

$$
G_{j}\left(\beta_{j}\right)=\arg \min _{\xi} \frac{1}{T} \sum_{t=1}^{T}\left\{\phi_{j}\left(x_{t+1}\left(\beta_{j}\right)\right)-g_{j}\left(\xi, S_{t}\left(\beta_{j}\right)\right)\right\}^{2}
$$

Note that, by doing this, we make sure that, if agents use $\beta$ to make their predictions, then $g\left(G(\beta), s_{t}(\beta)\right)$ yields the best forecast of $\phi\left(x_{t+1}(\beta)\right)$.

(iii) Our goal is to find the fixed point $\beta_{j}=G_{j}\left(\beta_{j}\right)$. To do this, we use a weighted average of the old parameters $\beta$ and the new estimates $G(\beta)$ for the next iteration, i.e., the parameters used in the next iteration $\tau$ are equal to $\beta^{\tau}=\lambda G\left(\beta^{\tau-1}\right)+(1-\lambda) \beta^{\tau}$, where $\lambda \in(0,1)$ forces the algorithm to take small steps, making the convergence easier.

Since households in our model are subject to occasionally binding limits, we have to be sure that the Kuhn Tucker conditions are satisfied every period when implementing step (i). To do this, the solution to the model is calculated as follows. (1) Each period, we first after substitute the true expectations with the approximating functions and calculate the 


\section{Financial Policy with Trading Constraints}

solution for the endogenous variables assuming that the trading limits are not binding. Since the Euler equations can be treated as equalities in this case, we use all of them, together with the other constraints of the model, to calculate the solution; (2) After doing this, we check if the asset demands obtained in the previous step do indeed satisfy the trading limits. If this is the case, we go to the next period and proceed as in (1). Otherwise, we impose the constraints and use the Euler equations of the unconstrained household and the other constraints to calculate the solution.

\section{REFERENCES}

Carceles-Poveda, E. (2005), "Capital Ownership under Market Incompleteness: Does it matter?", unpublished manuscript, SUNY at Stony Brook.

DeMarzo P.M. (1988), "An Extension of the Modigliani-Miller Theorem to Stochastic Economies with Incomplete Markets and Interdependent Securities", Journal of Economic Theory, 45, 353-369.

DenHaan W. J. and Marcet A. (1990), "Solving the Stochastic Growth Model by Parametrized Expectations", Journal of Business and Economic Statistics, 8, 31-34.

Detemple J., Gottardi P., and Polemarchakis H. (1995), "The Relevance of Financial Policy", The European Economic Review, 39, 1133-1154.

Dreze J. H. (1985), "(Uncertainty and) the Firm in GE Theory", Economic Journal, 95, $1-20$.

Duffie, D., and W. Shaffer (1986), "Equilibrium and the Role of the Firm in Incomplete Markets", unpublished manuscript.

Gottardi P., (1995), "An Analysis of the Conditions for the Validity of Modigliani-Miller Theorem with Incomplete Markets", Economic Theory, 5, 191-207.

Grossmann, S. J., and J., E. Stiglitz (1980), "Stockholder Unanimity in Making Production and Financial Decisions", The Quarterly Journal of Economics, 94, 543-566.

Grossmann, S. J., and J., E. Stiglitz (1977), "On Value Maximization and Alternative Objectives for the Firm", The Journal of Finance, 32, 389-402.

Modigliani F. and Miller M. H. (1958), "The Cost of Capital, Corporation Finance and the Theory of Investment", American Economic Review, 48, 261-297.

Modigliani F. and Miller M. H. (1963), "Corporate Taxes and the Cost of Capital: A Correction", American Economic Review, 53, 433-443.

Santos, M., and M. Woodford (1997), "Rational Asset Pricing Bubbles", Econometrica, 65, 19-57.

Stiglitz, J. (1969), "A Re-examination of the Modigliani Miller Theorem", Review of Economics and Statistics, 59.

Stiglitz, J. (1974), "On the Irrelevance of Corporate Financial Policy", The American Economic Review, 64, 851-866. 


\section{TABLES}

Table 1: Macroeconomic Statistics with $a^{i}\left(s^{t}\right) \geq 0.4$

\begin{tabular}{lcccc}
\hline \hline Series $(\mathrm{x})$ & $\mathrm{E} 1 \operatorname{std}(\mathrm{x}) / \operatorname{std}(\mathrm{y})$ & $\operatorname{corr}(\mathrm{x}, \mathrm{y})$ & $\mathrm{E} 2 \operatorname{std}(\mathrm{x}) / \operatorname{std}(\mathrm{y})$ & $\operatorname{corr}(\mathrm{x}, \mathrm{y})$ \\
\hline Output & 1.000 & 1.000 & 1.000 & 1.000 \\
Consumption & 0.521 & 0.191 & 0.595 & 0.193 \\
Investment & 3.785 & 0.930 & 3.636 & 0.973 \\
Capital Stock & 0.263 & 0.484 & 0.273 & 0.468 \\
Ind. Consumption & 4.947 & 0.047 & 4.601 & 0.051 \\
Ind. Income & 8.886 & 0.130 & 8.879 & 0.128 \\
\hline
\end{tabular}

The simulated data have been detrended with the HP filter $(\mathrm{x}=$ series, $\mathrm{y}=$ output $)$.

Table 2: Macroeconomic Statistics with $a^{i}\left(s^{t}\right) \geq-1$

\begin{tabular}{lcccc}
\hline \hline Series $(\mathrm{x})$ & $\mathrm{E} 1 \mathrm{std}(\mathrm{x}) / \operatorname{std}(\mathrm{y})$ & $\operatorname{corr}(\mathrm{x}, \mathrm{y})$ & $\mathrm{E} 2 \operatorname{std}(\mathrm{x}) / \operatorname{std}(\mathrm{y})$ & $\operatorname{corr}(\mathrm{x}, \mathrm{y})$ \\
\hline Output & 1.000 & 1.000 & 1.000 & 1.000 \\
Consumption & 0.142 & 0.373 & 0.127 & 0.161 \\
Investment & 3.388 & 0.995 & 3.522 & 0.995 \\
Capital Stock & 0.236 & 0.521 & 0.245 & 0.526 \\
Ind. Consumption & 6.129 & 0.019 & 5.533 & 0.021 \\
Ind. Income & 8.875 & 0.129 & 8.875 & 0.129 \\
\hline
\end{tabular}

The simulated data have been detrended with the HP filter $(\mathrm{x}=$ series, $\mathrm{y}=$ output). 
Financial Policy with Trading Constraints

\section{FIGURES}

Economy 1: $\left\{\alpha^{i}, c^{i}, a^{i}\right\}$ with $\kappa^{i}\left(s^{t}\right)=0.3 A_{1}\left(s^{t}\right)=0.3$
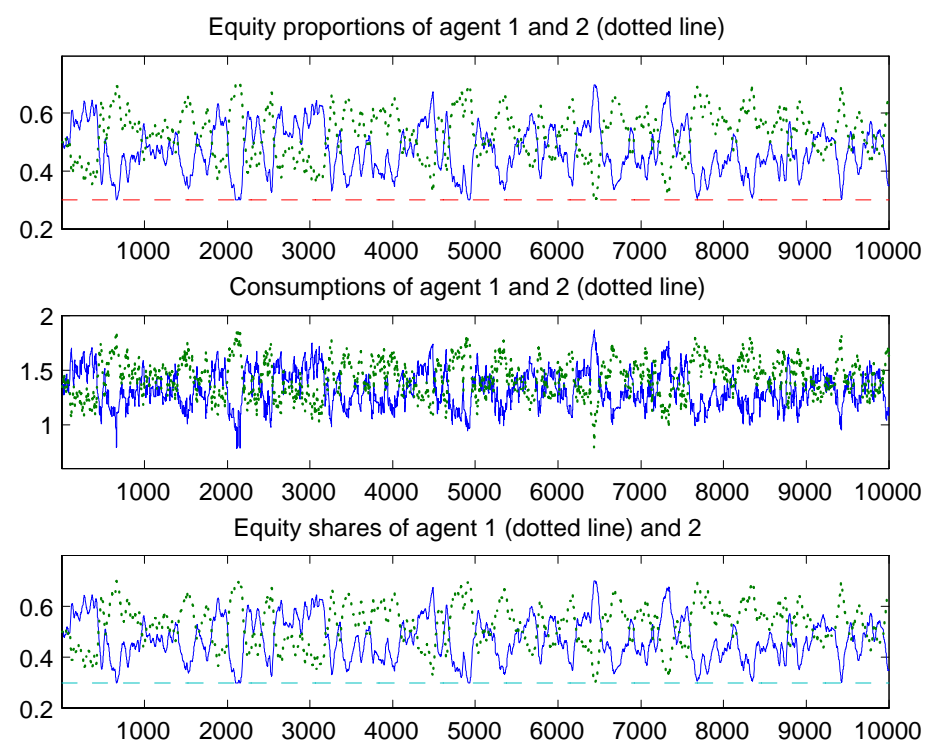

Figure 1

Economy 2: $\left\{\alpha^{i}, c^{i}, a^{i}\right\}$ with $\kappa^{i}\left(s^{t}\right)=0.3 A_{1}\left(s^{t}\right)$
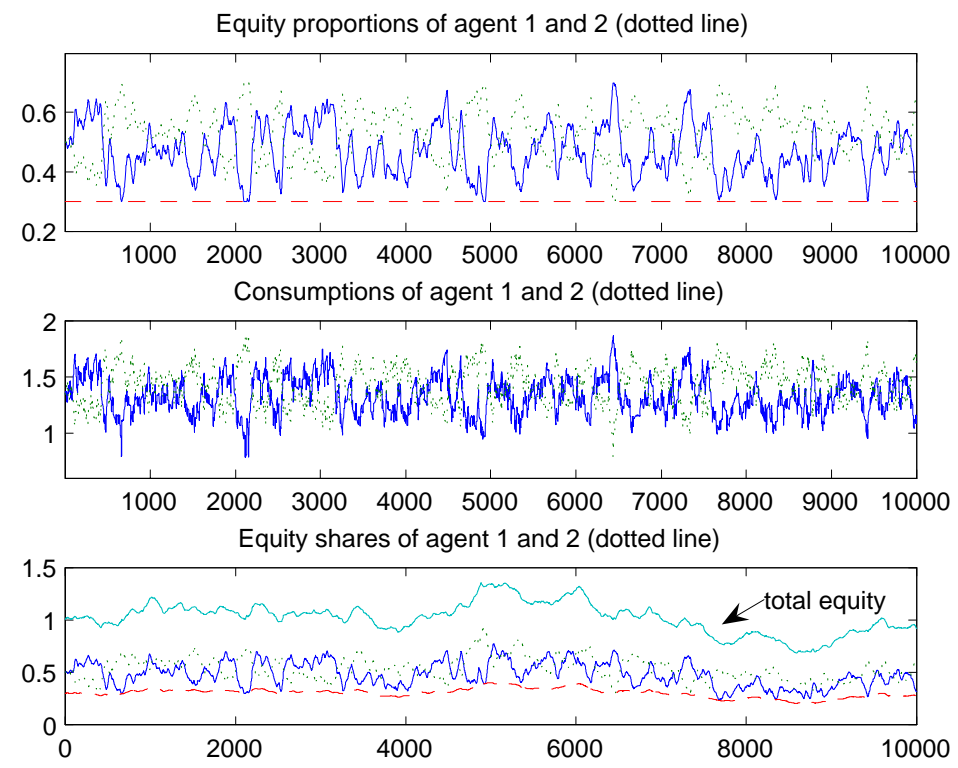

Figure 2 
Economies 1 and 2: $\left\{\alpha^{i}\right\}$ with $\kappa^{i}\left(s^{t}\right)=0.4 A_{1}\left(s^{t}\right)$ and $\kappa^{i}\left(s^{t}\right)=0.4$
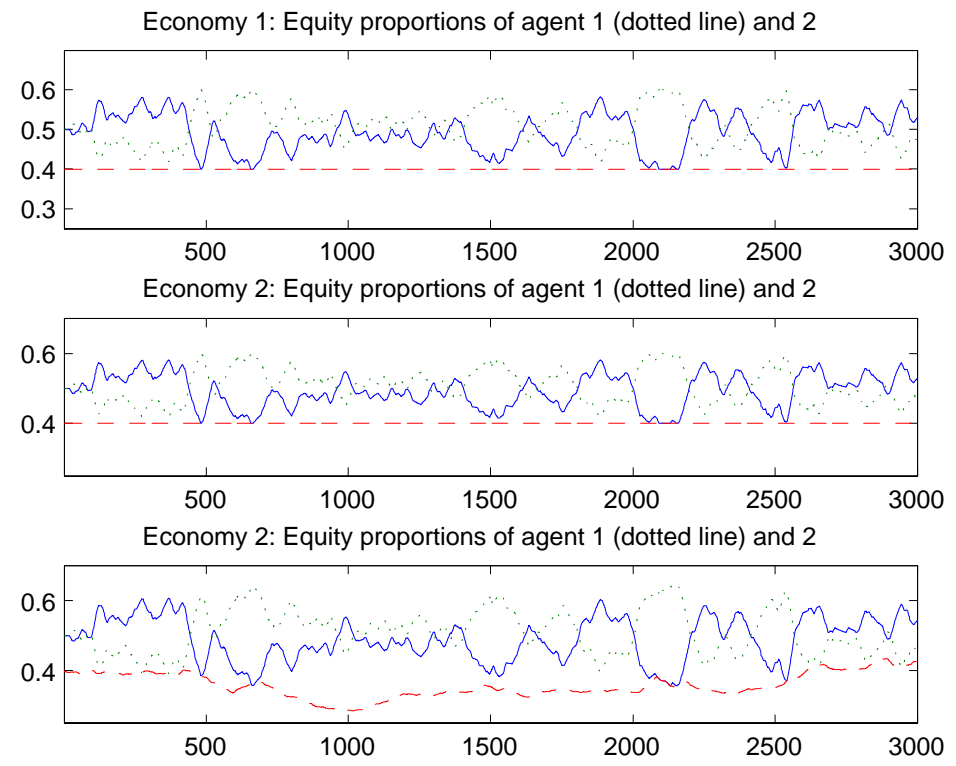

Figure 3

Economy 1 and 2: $\left\{a^{i}\right\}$ with $a^{i}\left(s^{t}\right) \geq-1$
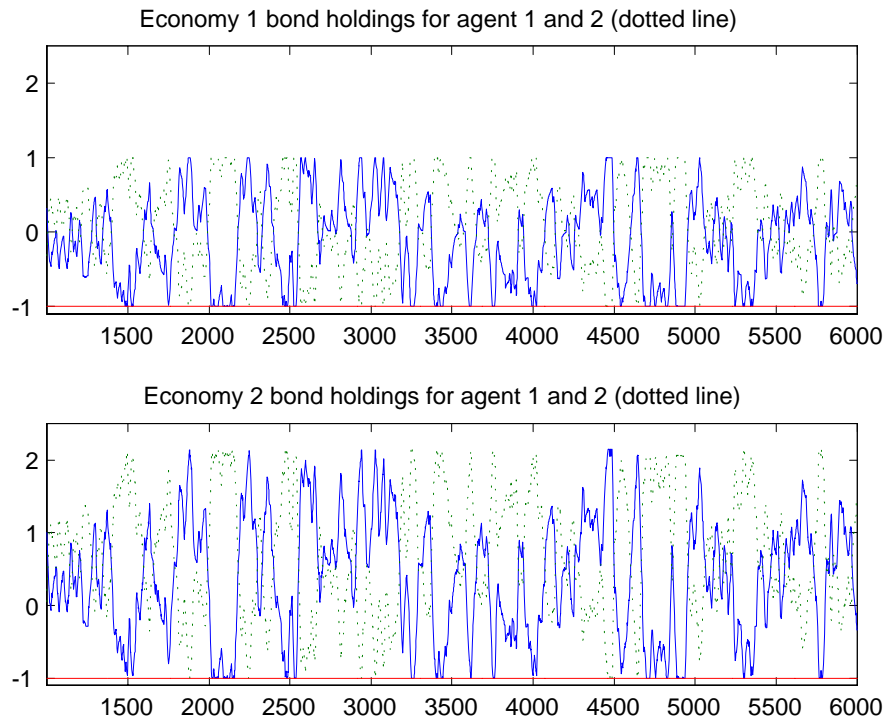

Figure 4 


\section{Financial Policy with Trading Constraints}

Economy 2: $\left\{a^{i}\right\}$ with $a^{i}\left(s^{t}\right) \geq-1$ and $a^{i}\left(s^{t}\right) \geq-1+\alpha^{i}\left(s^{t}\right) A_{2}\left(s^{t}\right)$
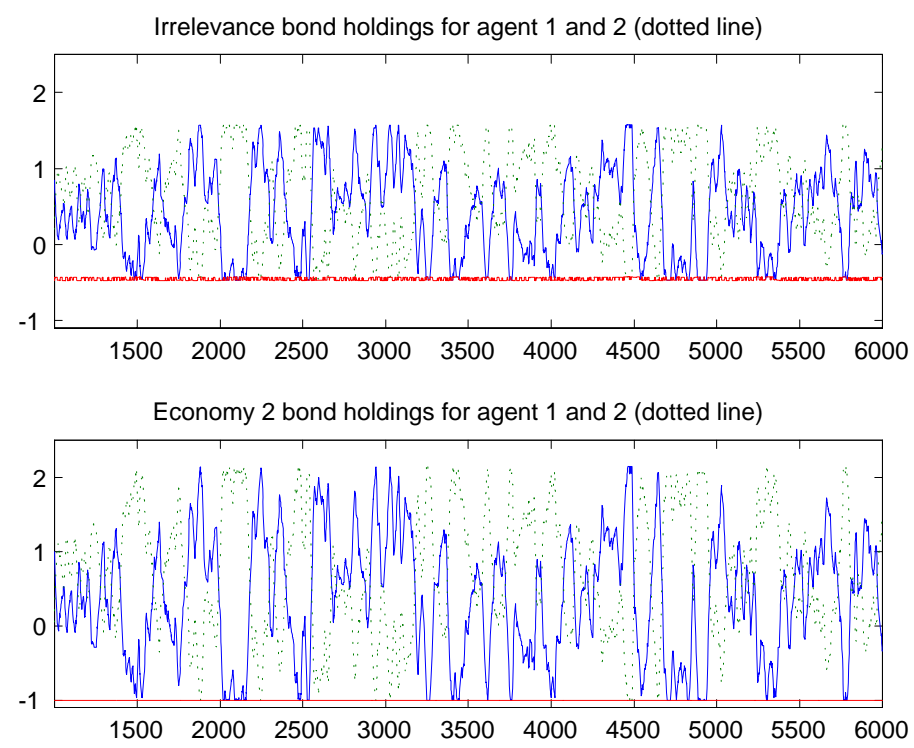

Figure 5

Economy 2: $\left\{K, \kappa^{i}\right\}$ with $a^{i}\left(s^{t}\right) \geq-1+\alpha^{i}\left(s^{t}\right) A_{2}\left(s^{t}\right)$
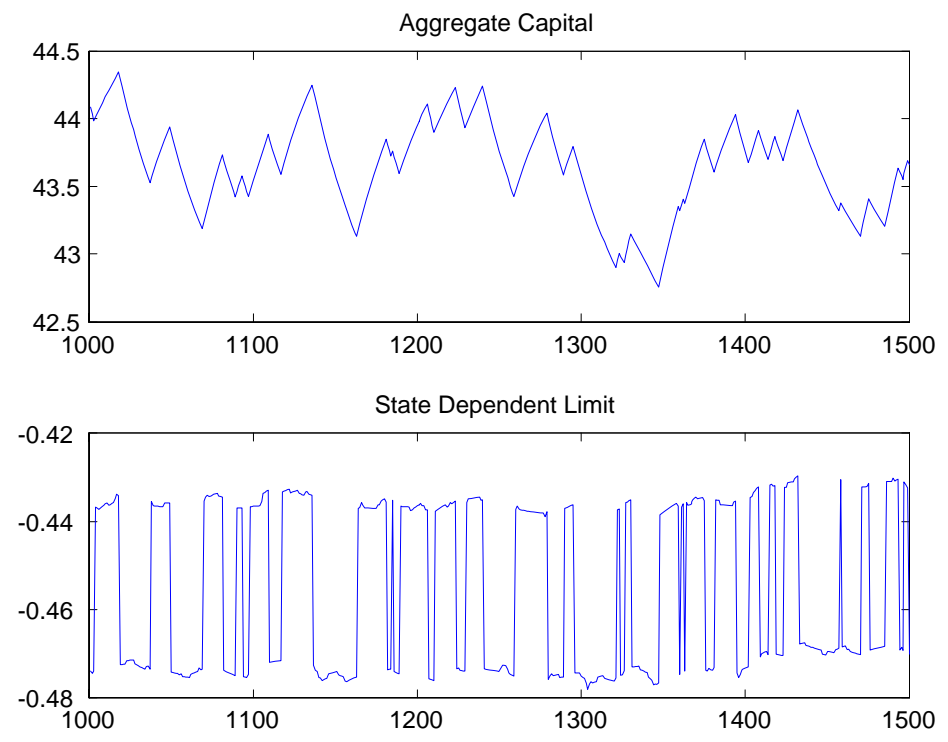

Figure 6 
Economy 1 and 2: Welfare with $a^{i}\left(s^{t}\right) \geq-1$

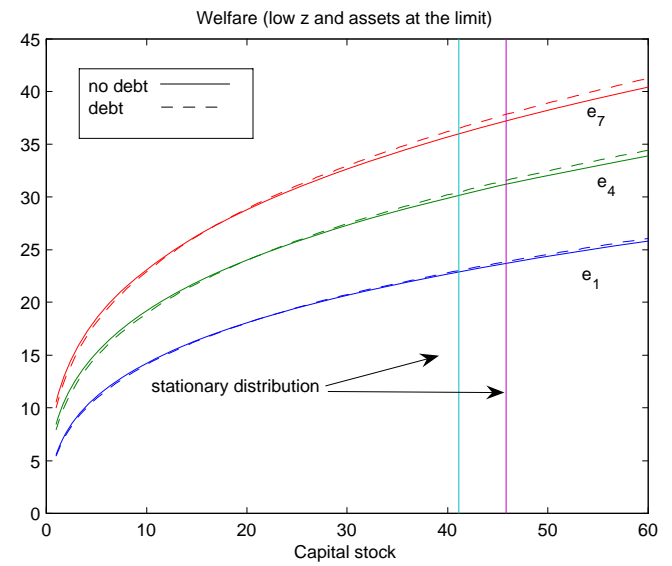

Welfare with assets at the limit

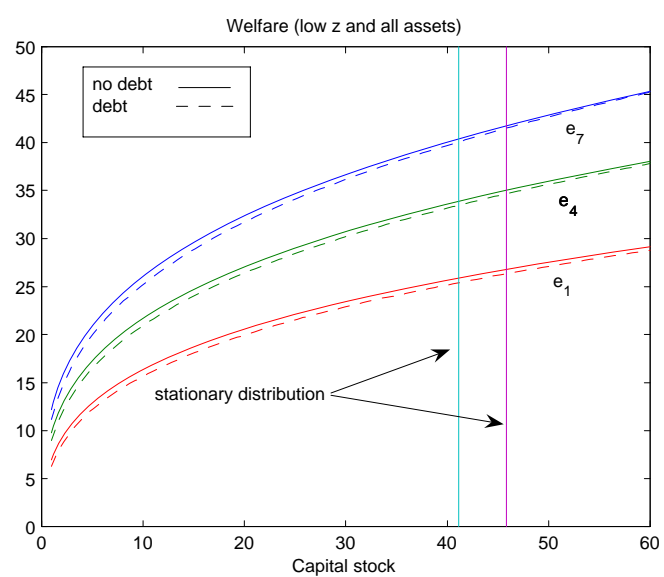

Welfare with all assets

Figure 7 